\title{
Atribuição de estados mentais e linguagem: um estudo de intervenção
}

\author{
Simone Ferreira da Silva Domingues \\ Universidade Cruzeirodo Sul - Universidade Guarulhos - SP \\ Maria Regina Maluf \\ Universidade de Sao Paulo - SP
}

\begin{abstract}
Resumo
A presente pesquisa teve por objetivo verificar os efeitos de uma intervenção sobre a habilidade de atribuição de estados mentais de crença e foi desenvolvida em três fases: pré-teste, intervenção e pós-teste. As crianças selecionadas foram escolhidas aleatoriamente para compor o grupo experimental e o grupo controle. A pesquisa foi feita com 44 crianças de ambos os sexos, de três a quatro anos de idade. A intervenção foi baseada na explicação de tarefas de crença falsa e acompanhada por demonstrações com a ajuda de gestos e de objetos, além da fala explicativa. Os resultados indicaram que as crianças do grupo experimental se beneficiaram com o procedimento de intervenção. As atividades favoreceram o surgimento da habilidade de atribuição de estados mentais de crença. Esses resultados dão sustentação às hipóteses que apontam a existência de uma relação entre a habilidade de atribuição de estados mentais e o desenvolvimento da linguagem.
\end{abstract}

Palavras-chave: Teoria da mente, crenças, desenvolvimento da linguagem.

\section{Attribution of mental states and language: A study of intervention}

\begin{abstract}
In this study we investigate the effects of an intervention on the ability of attributing mental states of belief. We developed the work in three phases: pre-test, intervention and post-tests. The selected children were assigned randomly to compose the experimental group and control group. Forty-four children of both sexes, 3 to 4 years old, participated in the study. The intervention was based on the explanation of false belief tasks and was supported by demonstrations with the help of gestures and objects, and explanatory speech. The results indicated that children in the experimental group benefited from the intervention procedure. The activities encouraged the emergence of the ability to attribute mental states of belief. These findings support the hypotheses that point to the existence of a relationship between the ability of attributing mental states and language development.
\end{abstract}

Keywords: Theory of mind, beliefs, language development.

\section{Atribución de estados mentales y lenguaje: un estudio de intervención}

\section{Resumen}

Este estudio tuvo por objetivo verificar los efectos de una intervención sobre la habilidad de atribución de estados mentales de creencia y se desarrolló en tres fases: pre-test, intervención y post-test. Los niños seleccionados fueron asignados al azar para formar el grupo experimental y el grupo control. La investigación se llevó a cabo con 44 niños de ambos sexos de 3 a 4 años de edad. A intervención tuvo por base la explicación de tareas de creencia falsa y fue acompañada por demostraciones con ayuda de gestos y de objetos, además de discurso explicativo. Los resultados indicaron que los niños del grupo experimental se beneficiaron del procedimiento de intervención. Las actividades favorecieron la aparición de la habilidad de atribución de estados mentales de creencia. Estos resultados sustentan hipótesis que indican la existencia de una relación entre la habilidad de atribución de estados mentales y el desarrollo de lenguaje.

Palabras clave: Teoría de la mente, creencias, desarrollo del language. 


\section{Introdução}

Numerosos estudos sobre o desenvolvimento da compreensão da mente do outro são encontrados na literatura psicológica sob a designação de teoria da mente, significando o entendimento que as crianças elaboram, durante os primeiros anos de vida, a respeito das emoções, intenções e crenças das pessoas com as quais interagem em seu cotidiano (Astington, Harris, \& Olson, 1988; Baron-Cohen, Leslie, \& Frith, 1985; Wimmer \& Perner, 1983).

As pesquisas sobre o desenvolvimento da teoria da mente são de grande importância, dadas as suas implicações na compreensão do desenvolvimento social da criança e suas possibilidades de aplicação na educação infantil, sobretudo em crianças de três a seis anos de idade.

Ao longo dos anos 80 e 90 vários estudos foram realizados para investigar a habilidade de compreensão da mente do outro (Deleau, 1996; Dias, 1993; Jenkins \& Astington, 1996; Roazzi \& Santana, 1999; Siegal \& Beattie, 1991) e se consolidaram utilizando o paradigma da crença falsa desenvolvido por Wimmer e Perner (1983). Assim, por exemplo, uma criança mostra que compreende a crença falsa de outra criança quando, observando a realidade, diz: "ele pensa que o chocolate está no armário, mas não está lá, porque a mãe dele o guardou noutro lugar". A criança neste exemplo demonstra compreender que as pessoas têm representações da realidade e que essas representações podem ser falsas.

A compreensão a respeito do que outras pessoas pensam é uma habilidade que se desenvolve durante os primeiros anos de vida e é essencial para a adaptação social da criança. Esse desenvolvimento parece estar relacionado à linguagem e vem sendo estudado em distintas culturas e idiomas (Antonietti, Liverta-Sempio, \& Marchetti, 2006; Astington \& Baird, 1995; Maluf, Gallo-Penna, \& Santos, 2011; Souza, 2008). Nas pesquisas de tipo experimental a relação entre teoria da mente e linguagem é estudada, sobretudo, por meio da aplicação de tarefas de crença falsa (Domingues \& Maluf, 2008; Rakh, Kornilov, Reich, Babyonyshev, \& Grigorenko (2011).

Alguns estudos experimentais encontrados na literatura, feitos com grupo experimental e grupo controle, demonstram que as crianças do grupo experimental que vivenciam atividades de conversas sobre personagens de histórias de livros ou vídeos apresentam um desempenho melhor nas tarefas de crença falsa, quando comparadas com crianças do grupo controle que não passaram por essas atividades (Appleton \& Reddy, 1996; Clements, Rustin \& McCallum, 2000; Guajardo \& Watson, 2002). Dois desses estudos experimentais encontrados na literatura (Appleton \& Reddy, 1996; Clements, e cols., 2000), que tratam do desenvolvimento da teoria da mente mediante aplicação de tarefas de crença falsa e conversação com as crianças, despertaram nosso interesse e estão na origem da presente pesquisa, uma vez que não foram identificados trabalhos de intervenção similares realizados com crianças brasileiras.
No estudo de Appleton e Reddy (1996) foi aplicado em crianças de três anos um procedimento de intervenção em que o experimentador explica a reação de surpresa de um protagonista em uma situação de crença falsa. A intervenção teve como objetivo favorecer a compreensão das crianças em tarefas tradicionais de crença falsa. $O$ estudo foi realizado com 47 participantes com idade média de três anos e seis meses. Além da tarefa de crença falsa utilizada no pré-teste, foi aplicada a escala British Picture Vocabulary Scale (BPVS). As crianças foram alocadas aleatoriamente no grupo controle ou no grupo experimental. O grupo experimental participou de oito sessões de discussões promovidas em torno de quatro videoclipes, de curta duração, por um período de duas semanas, em sessões de dez a quinze minutos. No programa de intervenção um adulto explicava a reação de surpresa de um ator que aparecia nas cenas dos videoclipes, após a inesperada transferência de um objeto. Foram quatro cenas diferentes, em que um protagonista desempenhava ações motivado por uma crença falsa quanto à localização de um objeto e manifestava expressão de surpresa. Cada intervenção envolvia lembrança do evento inicial e sua sequência, questionamento factual sobre o evento e explicação dos pensamentos e ações do protagonista do vídeo.

As crianças do grupo controle participavam de quatro sessões de dez a quinze minutos com o pesquisador, mas as sessões se limitavam à leitura de histórias de alguns livros. Ambos os grupos foram submetidos a um pós-teste, com tarefas de crença falsa, imediatamente após a quarta sessão de intervenção e a quarta sessão de leitura. Os resultados evidenciaram que os procedimentos de intervenção que consistiram em promover conversas e explicações para descrever a inesperada transferência de local do objeto contribuíram para o desenvolvimento da habilidade de atribuir crença falsa ao outro. Esses resultados mostraram também que as crianças que conversaram mais durante as sessões de intervenção obtiveram melhor desempenho nas tarefas de avaliação após o procedimento. Duas semanas após o primeiro pós-teste as crianças foram reavaliadas com os mesmos instrumentos. Esse segundo pós-teste mostrou que os resultados obtidos se mantiveram duas semanas após o experimento.

O outro estudo que investigou o efeito de uma intervenção na compreensão da crença falsa foi o realizado por Clements e cols. (2000). Participaram 91 crianças, com idade entre dois anos e dez meses meses e cinco anos, as quais foram divididas em três grupos: um grupo participou de uma "intervenção explicação", outro participou de uma "intervenção prática", e o terceiro foi mantido como grupo controle. Foram realizadas duas sessões de intervenção com os grupos experimentais. O grupo "intervenção explicação" recebeu explicações detalhadas sobre a situação de crença falsa e sobre suas respostas erradas ou corretas. Ao grupo da "intervenção prática" era apenas informado se as suas respostas estavam corretas ou incorretas. As crianças do grupo controle ouviram uma história neutra. Os resultados indicaram que apenas o grupo que recebeu a interven- 
ção em "explicação" teve uma melhora significativa no julgamento e justificativa das futuras ações de um protagonista em uma situação de crença falsa. Esses resultados sugerem que a explicação sobre os princípios subjacentes à situação de crença falsa é mais eficiente para levar a uma melhora no desempenho na tarefa do que apenas a informação sobre a resposta da criança estar correta ou não.

Os procedimentos utilizados nessas pesquisas e os resultados obtidos nos levaram a perguntar pelos possíveis resultados de aplicações similares a crianças brasileiras da mesma faixa etária que frequentam classes de educação infantil.

A presente pesquisa teve como objetivo verificar os efeitos de um procedimento de intervenção experimental com uso de linguagem explicativa de estados mentais, sobre a compreensão da crença falsa, em crianças de três e quatro anos de idade. Partiu-se da hipótese de que as conversações com crianças em situações lúdicas nas quais são explicitados estados mentais de crença dos personagens com uso de verbos mentais têm efeito positivo no desempenho de tarefas de crença falsa.

\section{Método}

Para medir o impacto do programa de intervenção sobre a compreensão de crença falsa utilizou-se um delineamento experimental com pré-teste, intervenção e dois pós-testes. O segundo pós-teste foi aplicado com o objetivo de verificar se os resultados obtidos permaneciam três semanas depois da aplicação do pós-teste 1 .

O projeto recebeu aprovação do Comitê de Ética em Pesquisa da Pontifícia Universidade Católica de São Paulo. Foi obtido o consentimento livre e esclarecido dos responsáveis pelas crianças e mantido o anonimato destas.

\section{Participantes}

Participaram da pesquisa 44 crianças de três anos a quatro anos e onze meses que frequentavam uma creche na cidade de São Paulo. A creche atende a população do bairro, constituída predominantemente por famílias de baixa renda.

Duas tarefas de crença falsa foram aplicadas como pré-teste e seleção dos participantes. Foram selecionadas para a pesquisa as crianças que não acertaram nenhuma dessas duas tarefas e foram excluídas as que mostraram acertos, uma vez que acertar tarefas de crença falsa indicava algum nível de capacidade de atribuição desse estado mental.

As tarefas aplicadas foram: a dos Smarties (Perner, Leekam, \& Wimmer, 1987) e a de Sally e Ann (Baron-Cohen e cols., 1985), ambas na forma adaptada por Dias, Soares e Sá (1994).

As 44 crianças selecionadas foram escolhidas aleatoriamente para comporem o grupo experimental (GE) e o grupo controle (GC). O GE foi composto por 22 crianças, sendo 11 meninas e 11 meninos, de 3 anos e 5 meses a 4 anos e 7 meses ( $M=3$ anos e 9 meses). O GC foi composto por 22 crianças, sendo 12 meninas e 10 meninos, com os mesmos extremos na faixa etária, com média de idade de 3 anos e 5 meses.

A aplicação do teste $t$ permitiu aceitar a equivalência dos grupos quanto à idade $(t=1,676$ e $p=0,101)$.

\section{Instrumentos}

O procedimento de intervenção em crença falsa foi baseado no estudo de Appleton e Reddy (1996) e utilizou quatro histórias que permitiam verificar se a criança mostrava habilidade de atribuição de crença falsa aos personagens (Anexo 1).

Para o pós-teste 1 foram utilizadas duas tarefas de crença falsa, semelhantes às aplicadas no pré-teste: a tarefa da caixa de fósforos (Hogrefe, Wimmer, \& Perner, 1986) e a tarefa utilizada por Avis e Harris (1991). A tarefa 1, designada como predição de conduta do tipo conteúdo inesperado, tem como estrutura apresentar à criança uma caixa de fósforos com rótulo que indica o conteúdo da caixa; mas ao abri-la, a criança constata a presença de outro conteúdo. Pergunta-se à criança o que diria um amiguinho que desconhecesse o conteúdo da caixa, quando perguntado sobre seu conteúdo. A tarefa 2, designada como predição de conduta do tipo história de engano, tem como estrutura e conteúdo a participação de dois personagens, brincando cada qual com um objeto. O personagem 1 guarda seu objeto num determinado lugar e sai de cena; o personagem 2 aproveita a ausência do primeiro, pega o objeto guardado e o esconde em outro local. O personagem 1 volta para recuperar o objeto. A criança deve predizer se ele vai procurar o objeto onde o deixou ou onde o personagem 2 o escondeu (Anexo 2).

No pós-teste 2 as crianças foram avaliadas com as tarefas da caixa de lápis de cor (Perner e cols., 1987) e do garoto Maxi, aqui denominado João (Wimmer \& Perner, 1983). A tarefa 3 tem como estrutura e conteúdo a apresentação, à criança, de duas caixas. Uma caixa tem um rótulo que indica o conteúdo da caixa (lápis de cor) e a outra caixa é igual, mas sem rótulo, toda branca. O experimentador pega a primeira caixa e pergunta à criança o que há no seu interior. Quando a criança responde corretamente, uma vez que ela conhece o rótulo, o experimentador abre a caixa e mostra que ela está vazia. Em seguida ele pega a segunda caixa, sem rótulo, e pergunta à criança o que há no interior da caixa. Em geral as crianças tentam adivinhar ou dizem que não sabem. $O$ experimentador então abre a caixa e mostra que ela contém lápis de cor. Ele então pergunta: "O que você acha que diria seu amiguinho se perguntarmos para ele o que há nesta caixa?". Espera-se que a criança compreenda que o amiguinho que desconhece o conteúdo das caixas não será capaz de predizer o conteúdo da caixa sem rótulo. Esse tipo de tarefa é designado como predição de conduta do tipo conteúdo inesperado. A tarefa 4 tem como estrutura e conteúdo a participação de dois personagens que estão brincando, cada qual com um objeto. $\mathrm{O}$ 
personagem 1 guarda seu objeto num determinado lugar e sai de cena; o personagem 2 aproveita a ausência do primeiro, pega o objeto guardado e o esconde em outro local. $\mathrm{O}$ personagem 1 volta para recuperar o objeto. A criança deve dizer se o personagem 1 vai procurar o objeto onde o deixou ou onde o personagem 2 o escondeu. Esse tipo de tarefa é designado como predição de conduta com tipo história de engano (Anexo 2).

O primeiro pós-teste foi aplicado no dia seguinte à quarta e última sessão de intervenção, começando sempre com as primeiras crianças que haviam passado pela experiência e intercalando com as crianças do grupo controle. O segundo pós-teste foi aplicado três semanas após o primeiro pós-teste.

Nas avaliações de crença falsa, para cada tarefa foi atribuído 1 (um) ponto para a resposta correta e 0 (zero) para a resposta incorreta.

\section{Procedimento de intervenção}

Antes de iniciar o estudo o pesquisador frequentou a creche pelo período de um mês, com o objetivo de familiarizar as crianças com sua presença. Após esse período deu início à aplicação das tarefas de crença falsa do pré-teste. As tarefas foram aplicadas de forma individual e nas dependências da creche.

A intervenção foi aplicada em quatro sessões individuais, com duração de dez a quinze minutos, no período de duas semanas, sendo duas sessões por semana. Em cada uma delas foi utilizada uma história e entregue o material para manuseio da criança. As sessões foram gravadas em áudio e complementadas com anotações sobre os comportamentos não verbalizados das crianças.

Para contar as histórias foi utilizado um cenário, montado numa casinha de madeira medindo $67 \mathrm{~cm}$ de largura, $49 \mathrm{~cm}$ de profundidade e $44 \mathrm{~cm}$ de altura. Nela eram colocados os protagonistas, o que permitia criar um cenário lúdico que agradava às crianças participantes (figura 1).

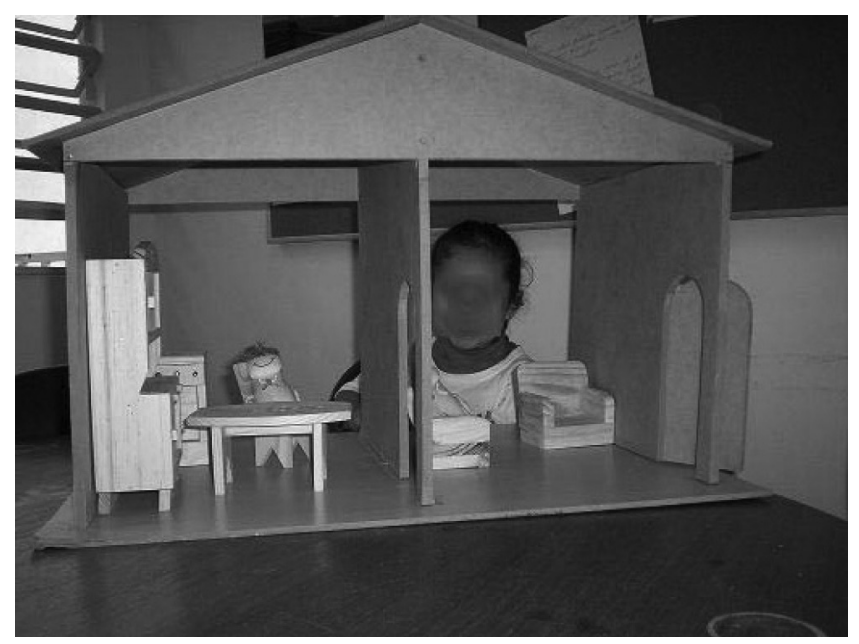

Figura 1. Cenário utilizado na intervenção
Em todas as sessões, o experimentador contava a história e depois conversava com a criança sobre a trama. $\mathrm{O}$ experimentador interagia com a criança manipulando os diferentes materiais e personagens e falava com ela utilizando termos de atribuição de estados mentais de desejo, intenção e crença, como querer, gostar, acreditar e pensar.

Antes de iniciar a história o pesquisador conversa com a criança sobre o material do cenário, pergunta se ela conhece e sabe nomear os objetos e permite que ela os manipule. Em seguida solicita que a criança preste atenção à história que ele vai contar para que depois possam conversar sobre ela.

Como ilustração apresenta-se aqui uma sessão de intervenção utilizando a história do trenzinho:

Este bonequinho chama-se Carlos e ele gosta muito de brincar de trenzinho. Ele estava brincando com seu trenzinho no chão da sala. Aí, ele ficou com sede, pegou o trenzinho e foi até a cozinha pegar um refrigerante. Ele colocou o trenzinho em cima da mesa, pegou a garrafa de refrigerante e voltou para a sala. Sentou no sofá para tomar o refrigerante. Enquanto isso, o seu amigo entrou na cozinha e viu o trenzinho em cima da mesa. Ele pegou o trenzinho, colocou no assento da cadeira e foi embora. Aí o Carlos acabou de tomar o refrigerante e lembrou-se do trenzinho que havia deixado em cima da mesa, lá na cozinha. Aí ele foi buscar o trenzinho na cozinha, e quando ele foi pegar o trenzinho, que deixou em cima da mesa, o trenzinho não estava mais lá. Ele ficou surpreso!

Manipulando o boneco, o pesquisador perguntava: "Por que o Carlos achava que o trenzinho estava em cima da mesa? Aguardava a resposta da criança e continuava, questionando, sempre no sentido de recuperar os elementos da história e com o objetivo de chegar ao desfecho, onde ocorre a atribuição de crença falsa. "Por que o Carlos voltou para buscar o trenzinho na cozinha"? Mas quando ele chegou à cozinha, ele ficou surpreso porque o trenzinho não estava lá. O que você acha que aconteceu"?

Caso a criança não respondesse, o experimentador fornecia a resposta correta, manipulando o boneco e os objetos:

Como ele deixou na cozinha, ele pensava que ainda estivesse lá, pois ele não sabia que o amigo dele tinha colocado o trenzinho no assento da cadeira. Por que ele não sabia? Onde ele estava quando o amigo pegou o trenzinho?

Quando a criança, espontaneamente, não mostrava compreensão de crença falsa, o experimentador fornecia a resposta correta, explicando no contexto da história. "Quando o amigo pegou o trenzinho Carlos não viu, porque naquele momento ele estava na sala. Assim, ele acreditava que o trenzinho continuava em cima da mesa, onde ele o deixado".

Com as crianças do grupo controle foram utilizadas outras atividades, com o objetivo de controlar o chamado efeito de Hawthorne, decorrente do simples fato de estar participando de atividades de intervenção. Foram utilizadas 
quatro atividades que não incluíam linguagem, de modo a não concorrer para o desenvolvimento da habilidade de compreender e atribuir estados mentais. As atividades propostas e realizadas pelas crianças foram: desenho, massinha, colagem e quebra-cabeça.

Foram realizadas quatro sessões com duração aproximada de dez minutos. Em cada sessão foi entregue o material para o manuseio da criança, atividade que ocorreu ao longo de duas semanas, com a realização de duas sessões por semana.
A tabela 1 apresenta as idades e número de acertos nas tarefas de crença falsa das crianças do grupo experimental (GE) e do grupo controle (GC), no pós-teste 1 e no pós-teste 2.

Como se pode verificar na tabela 1 , no pós-teste 1 quatro crianças do grupo experimental (GE) acertaram a tarefa 1 e uma criança do grupo controle acertou essa tarefa. Na tarefa 2, treze crianças do grupo experimental (GE) deram a resposta correta, ou seja, compreenderam a falsa crença do personagem da história, enquanto somente duas crianças do grupo controle (GC) deram indício dessa compreensão.

Foi feito um tratamento estatístico para comparação dos escores obtidos no pós-teste 1 pelo grupo experimental (GE) e pelo grupo controle (GC), aplicando-se o teste do $x^{2}$ (qui-quadrado).

Tabela 1. Escores das crianças do grupo experimental (GE) e do grupo controle (GC) nas tarefas de crença falsa 1,2,3 e 4, aplicadas no pós-teste 1 e no pós-teste 2

\begin{tabular}{|c|c|c|c|c|c|c|c|c|c|c|c|}
\hline \multirow[b]{3}{*}{ Criança } & \multirow[b]{3}{*}{ Idade } & \multicolumn{4}{|c|}{ Grupo Experimental } & \multirow[b]{3}{*}{ Criança } & \multirow[b]{3}{*}{ Idade } & \multicolumn{4}{|c|}{ Grupo Controle } \\
\hline & & \multicolumn{2}{|c|}{$\begin{array}{c}\text { Pós- } \\
\text { Teste } 1\end{array}$} & \multicolumn{2}{|c|}{$\begin{array}{c}\text { Pós- } \\
\text { Teste } 2\end{array}$} & & & \multicolumn{2}{|c|}{$\begin{array}{c}\text { Pós- } \\
\text { Teste } 1\end{array}$} & \multicolumn{2}{|c|}{$\begin{array}{c}\text { Pós- } \\
\text { Teste } 2\end{array}$} \\
\hline & & $\mathrm{T} 1$ & $\mathrm{~T} 2$ & T3 & $\mathrm{T} 4$ & & & $\mathrm{~T} 1$ & $\mathrm{~T} 2$ & $\mathrm{~T} 3$ & $\mathrm{~T} 4$ \\
\hline 1 & $3 ; 5$ & 0 & 0 & 0 & 0 & 1 & $3 ; 5$ & 0 & 0 & 0 & 0 \\
\hline 2 & $3 ; 6$ & 0 & 0 & 0 & 0 & 2 & $3 ; 6$ & 0 & 0 & 0 & 0 \\
\hline 3 & $3 ; 6$ & 0 & 1 & 1 & 1 & 3 & $3 ; 6$ & 0 & 0 & 0 & 0 \\
\hline 4 & $3 ; 7$ & 0 & 0 & 0 & 0 & 4 & $3 ; 6$ & 0 & 0 & 0 & 0 \\
\hline 5 & $3 ; 8$ & 1 & 1 & 0 & 0 & 5 & $3 ; 7$ & 0 & 0 & 0 & 0 \\
\hline 6 & $3 ; 10$ & 0 & 0 & 0 & 0 & 6 & $3 ; 8$ & 0 & 0 & 1 & 0 \\
\hline 7 & $3 ; 11$ & 0 & 1 & 1 & 1 & 7 & $3 ; 9$ & 1 & 0 & 0 & 0 \\
\hline 8 & $3 ; 11$ & 0 & 0 & 0 & 1 & 8 & $3 ; 10$ & 0 & 0 & 0 & 0 \\
\hline 9 & $4 ; 0$ & 0 & 1 & 0 & 1 & 9 & $3 ; 10$ & 0 & 0 & 0 & 0 \\
\hline 10 & $4 ; 0$ & 0 & 1 & 1 & 0 & 10 & $3 ; 10$ & 0 & 0 & 0 & 0 \\
\hline 11 & $4 ; 0$ & 0 & 1 & 0 & 1 & 11 & $3 ; 10$ & 0 & 0 & 0 & 0 \\
\hline 12 & $4 ; 1$ & 0 & 0 & 1 & 0 & 12 & $3 ; 10$ & 0 & 0 & IIIII & IIIII \\
\hline 13 & $4 ; 1$ & 0 & 1 & 0 & 0 & 13 & $3 ; 11$ & 0 & 0 & 0 & 0 \\
\hline 14 & $4 ; 2$ & 0 & 0 & 0 & 0 & 14 & $3 ; 11$ & 0 & 0 & 0 & 0 \\
\hline 15 & $4 ; 2$ & 0 & 1 & 0 & 1 & 15 & $4 ; 0$ & 0 & 1 & 0 & 0 \\
\hline 16 & $4 ; 3$ & 0 & 0 & 1 & 0 & 16 & $4 ; 0$ & 0 & 0 & 0 & 0 \\
\hline 17 & $4 ; 4$ & 1 & 1 & 1 & 1 & 17 & $4 ; 1$ & 0 & 0 & 0 & 0 \\
\hline 18 & $4 ; 4$ & 0 & 1 & 1 & 1 & 18 & $4 ; 1$ & 0 & 0 & 0 & 0 \\
\hline 19 & $4 ; 5$ & 1 & 1 & 1 & 0 & 19 & $4 ; 5$ & 0 & 0 & 0 & 0 \\
\hline 20 & $4 ; 5$ & 0 & 1 & 1 & 1 & 20 & $4 ; 5$ & 0 & 0 & 0 & 0 \\
\hline 21 & $4 ; 6$ & 1 & 0 & 0 & 0 & 21 & $4 ; 6$ & 0 & 0 & 0 & 0 \\
\hline 22 & $4 ; 7$ & 0 & 1 & 1 & 1 & 22 & $4 ; 7$ & 0 & 1 & 1 & 1 \\
\hline \multicolumn{2}{|c|}{ Total de Acertos } & 4 & 13 & 10 & 10 & \multicolumn{2}{|c|}{ Total de Acertos } & 1 & 2 & 2 & 1 \\
\hline
\end{tabular}


Na tarefa 1, a baixa frequência dos resultados (GE= 4 e $\mathrm{GC}=1$ ) não permitiu conclusões baseadas em análise estatística. Em valores brutos o GE teve mais acertos do que o GC.

Na tarefa 2, o valor do teste $x^{2}=12,239(p=0,000)$, apresentou diferença significativa entre os resultados obtidos pelas crianças do grupo experimental (GE) e do grupo controle (GC). Observa-se que existe diferença significativa no desempenho entre os dois grupos $(p=0,001)$. Conclui-se que houve um efeito positivo do procedimento de intervenção, uma vez que o grupo experimental (GE) obteve desempenho significativamente melhor que o grupo controle (GC).

Em síntese, pode-se afirmar que os resultados indicaram efeitos do procedimento de intervenção sobre a habilidade de atribuição de estados mentais de crença na tarefa 2, que envolve predição de conduta com história de engano, e na tarefa 1, que envolve predição de conduta com conteúdo inesperado.

De acordo com o delineamento do estudo, o pós-teste 2 foi aplicado três semanas depois do pós-teste 1, com o objetivo de verificar se haviam se mantido os efeitos obtidos após a intervenção.

Como se pode observar na tabela 1, dez crianças do grupo experimental (GE) mostraram acertos na tarefa 3 e duas crianças do grupo controle (GC) apresentaram acertos na mesma tarefa.

O valor do teste $x^{2}$ no cruzamento de escores obtidos pelas crianças dos grupos experimental e controle, com a tarefa 3, mostrou um valor de 6,894 ( $p=0,009)$. Observa-se diferença significativa no desempenho entre os dois grupos $(p<0,01)$, permitindo concluir que houve um efeito positivo do procedimento de intervenção, uma vez que o grupo experimental (GE) obteve desempenho significativamente melhor que o do grupo controle (GC).

Na tarefa 4, dez crianças do grupo experimental (GE) obtiveram acerto, enquanto somente uma criança do grupo controle acertou a mesma tarefa. O valor do teste $x^{2}=9,345$ $(p=0,002)$, no cruzamento de escores obtidos pelas crianças do grupo experimental (GE) e do grupo controle (GC), com a tarefa 4 , sugere diferença significativa entre os dois grupos $(p<0,01)$. Conclui-se que houve um efeito positivo do procedimento de intervenção, uma vez que o grupo experimental (GE) obteve desempenho, significativamente, melhor que o grupo controle (GC).

Esses resultados permitem afirmar que os efeitos da intervenção se mantiveram após três semanas, para as crianças do grupo experimental (GE), sugerindo que os ganhos permaneceram.

Em síntese, é possível afirmar que as crianças se beneficiaram com o procedimento de intervenção que envolveu conversações com o uso de verbos mentais. As atividades realizadas favoreceram o surgimento da habilidade de atribuição de estados mentais de crença e esses efeitos se mantiveram no grupo experimental (GE) após três semanas. Esse achado deu sustentação à nossa hipótese de que o procedimento de intervenção que utiliza conversações com crianças em situações lúdicas nas quais são explicitados estados mentais de crença dos personagens, com uso de verbos mentais, produz efeito positivo no desempenho de tarefas de crença falsa.

\section{Discussão}

A presente pesquisa teve como objetivos verificar o efeito de um procedimento de intervenção experimental com uso de linguagem explicativa de estados mentais, sobre a compreensão da crença falsa, em crianças de 3 e 4 anos de idade e testar se esse efeito se mantém após três semanas. Os resultados indicaram que as crianças do grupo experimental (GE) se beneficiaram com o procedimento de intervenção e que as atividades realizadas favoreceram o surgimento de respostas corretas nas tarefas que avaliam a habilidade de atribuição de estados mentais de crença. Ademais, os efeitos se mantiveram após três semanas.

Esses achados permitiram aceitar a hipótese da pesquisa, de que crianças que frequentam classes de educação infantil podem beneficiar-se de interações linguísticas realizadas em situações lúdicas durante as quais são explicados estados mentais de crença dos personagens, com uso intencional de verbos mentais. A ênfase na narrativa e a frequência de conversas sobre estados mentais com as crianças parecem ter beneficiado seu desempenho nas tarefas de crença falsa.

Esses resultados estão de acordo com outros encontrados na literatura (Antonietti e cols., 2006; Astington \& Baird, 1995; Rakhlin e cols., 2011). De modo mais específico, confirmaram os achados dos estudos de Appleton e Reddy (1996) e de Clements e cols. (2000), ponto de partida deste estudo. Os autores mostraram que a linguagem utilizada em contextos de conversação foi proveitosa para favorecer a compreensão social sob a forma de habilidade de atribuição de estados mentais de crença.

Muitos pesquisadores argumentam que a linguagem oral desempenha um papel causal no desenvolvimento da compreensão de crença falsa; no entanto persistem discussões sobre o papel preciso que a linguagem desempenha, devido à possibilidade de ela ser operacionalizada e avaliada de diferentes maneiras (Deleau, Maluf, \& Panciera, 2008). Neste estudo, considerou-se a linguagem oral tal como ela se mostra em contextos de conversações, que habitualmente ocorrem na família e na escola. Nessas condições foi possível concluir que conversações realizadas com as crianças, sobre eventos que implicam ações mentais, podem favorecer o desenvolvimento da habilidade de atribuir crença ao outro, sendo essa aquisição de grande importância para a adaptação social das crianças. Como afirma Bruner (2001), na linguagem cotidiana pouco se fala sobre termos mentais - como pensar, acreditar e lembrar. $O$ que se verifica é que esses termos passam o tempo todo despercebidos, sendo utilizados somente em algumas situações. "Usar estas palavras requer que a criança entenda não apenas as palavras, mas sua contextualização na sociedade ao seu redor" (Bruner, 2001, p.108). 
Estudos futuros sobre as relações entre linguagem e o desenvolvimento da atribuição de estados mentais deverão esclarecer essa importante relação, com o uso de procedimentos que permitam separar, para fins de análise, as diferentes dimensões da linguagem. Os resultados do presente estudo permitiram concluir que o conhecimento do modo como as crianças adquirem noções sobre estados mentais, em situações de conversação, é da maior importância para a educação familiar e escolar. O estudo também permite recomendar que essa estratégia seja utilizada, tanto na família quanto na escola, para favorecer a compreensão social nos primeiros anos de vida.

\section{Referências}

Antonietti, A., Liverta-Sempio, O., \& Marchetti, A. (Eds.). (2006). Theory of mind and language in developmental contexts. New York: Springer Science.

Astington, J. W., \& Baird, J. A. (Eds.). (1995). Why language matters for theory of mind. Oxford, NY: Oxford University Press.

Astington, J. W., Harris, P. L., \& Olson, D. R. (Eds). (1988). Developing theories of mind. New York: Cambridge University Press.

Appleton, M., \& Reddy, V. (1996). Teaching three year-olds to pass false belief tests: A conversational approach. Social Development, 5(3), 275-291.

Avis, J. \& Harris, P.L. (1991). Belief-Desire reasoning among Baka children: Evidence for a universal conception of mind. Child Development, 2, 40-47.

Baron-Cohen, S., Leslie, A. M., \& Frith, U. (1985). Does the autistic child have a 'theory of mind'? Cognition, 21, 37-46.

Bruner, J. (2001). A cultura da educação. Porto Alegre: Artmed Editora.

Clements, W. A., Rustin, C. L., \& McCallun, S. (2000). Promoting the transition from implicit to explicit understanding: A training study of false belief. Developmental Science, 3(1), 81-92.

Deleau, M. (1996). L'attribution d'états mentaux chez des enfants sourds et entendants : une approche du rôle de l'experience langagière sur une théorie de l'esprit. Bulletin de Psychology, 50(427), 48-56.

Deleau, M., Maluf, M. R., \& Panciera, S. D. P. (2008). O papel da linguagem no desenvolvimento de uma teoria da mente: Como e quando as crianças se tornam capazes de representações de estados mentais. Em T. M Sperb \& M. R. Maluf (Orgs.), Desenvolvimento sociocognitivo: Estudos brasileiros sobre "Teoria da Mente" (pp. 93-130). São Paulo: Vetor.

Dias, M. G. B. B. (1993). O desenvolvimento do conhecimento da criança sobre a mente. Psicologia: Teoria e Pesquisa, 9(3), 587600.

Dias, M. G. B. B., Soares, G. B., \& Sá, T. P. (1994). Conhecimento sobre a mente e compreensão sobre as intenções do experimentador. Psicologia: Teoria e Pesquisa, 10(2), 221-229.

Domingues, S. F. S., \& Maluf, M. R. (2008). Compreendendo estados mentais: Procedimentos de pesquisa a partir da tarefa original de crença falsa. Em T. M. Sperb \& M. R. Maluf (Orgs.), Desenvolvimento sociocognitivo: Estudos brasileiros sobre "Teoria da Mente" (pp. 11-31). São Paulo, SP: Vetor.

Guajardo, N. R., \& Watson, A. C. (2002). Narrative discourse and theory of mind development. Journal of Genetic Psychology, 163, 305-325.

Hogrefe, G., Wimmer, H., \& Perner, J. (1986). Ignorance versus false belief: a developmental lag in attribution of epistemic states. Child development, 57, 567-586.

Jenkins, J. M., \& Astington, J. W. (1996). Cognitive factors and family structure associated with theory of mind development in young children. Developmental Psychology, 32(1), 70-78.

Maluf, M. R., Gallo-Penna, E. C., \& Santos, M. J. (2011). Atribuição de estados mentais e compreensão conversacional: Estudo com pré-escolares. Paidéia, 21(48), 41-50.

Perner, J., Leekman, S., \& Wimmer, H. (1987). Three-year-old's difficulty with false belief: The case for a conceptual deficit. British Journal of Developmental Psychology, 5, 125-137.

Rakhlin, N., Kornilov, S. A., Reich, J., Babyonyshev, M., Koposov, R., \& Grigorenko, E. L. (2011). The relationship between syntactic development and theory of mind: Evidence from a smallpopulation study of a developmental language disorder. Journal of Neurolinguistics, 24, 476-496.

Roazzi, A., \& Santana, S. M. (1999). Teoria da mente: efeito da idade, do sexo e do uso de atores animados e inanimados na inferência de estados mentais. Psicologia: Reflexão e Crítica, 12(2), 307-330.

Siegal, M., \& Beattie, K. (1991). Where to look first for children's knowledge of false beliefs. Cognition, 38, 1-12.

Souza, D. H. (2008). De onde e para onde? As interfaces entre linguagem, teoria da mente e desenvolvimento social. Em T. M. Sperb \& M. R. Maluf (Orgs.), Desenvolvimento sociocognitivo: Estudos brasileiros sobre "Teoria da Mente" (pp. 33-54). São Paulo: Vetor 
Wimmer, H., \& Perner, J. (1983). Beliefs about beliefs: Representation and constraining function of wrong beliefs in young children's understanding of deception. Cognition, 13, 103-128.

\section{Anexos}

\section{Anexo 1 - Descrição das 4 histórias e material que compôs os cenários}

Primeira história - cena do refrigerante

Pedro põe o refrigerante em cima da mesa e vai ao quintal, para jogar bola. Enquanto ele está jogando bola, João entra na cozinha, pega o refrigerante e o coloca no armário da cozinha. Pedro para de jogar bola e volta à cozinha para tomar seu refrigerante; olha na mesa e fica surpreso porque não encontra o refrigerante, lá

Material - O cenário será composto por uma maquete de casa, feita em madeira, dois bonecos, uma garrafa de refrigerante, um armário, uma bola, uma mesa.

Segunda história - cena do trenzinho

Carlos está sentado na sala brincando com seu trenzinho. Ele sai da sala com seu trenzinho na mão e vai para a cozinha pegar um refrigerante. Enquanto pega o refrigerante, põe o trenzinho em cima da mesa. Depois que pega o refrigerante, volta para a sala. Um amigo chega na cozinha e vê o trenzinho em cima da mesa, pega o trenzinho e o coloca no assento da cadeira. Carlos volta para a cozinha à procura de seu trenzinho que ficara sobre a mesa. Quando chega na cozinha, ele olha para a mesa e fica surpreso, pois o trenzinho não está mais lá.

Material - O cenário será composto por uma maquete de casa, feita em madeira, dois bonecos, um trenzinho, uma garrafa de refrigerante, uma mesa, uma cadeira e um sofá.

\section{Terceira história - esconde-esconde}

Bruno e Mateus estão brincando de esconde-esconde. Bruno fica de costas, fecha seus olhos e começa bater cara, contando até dez. Mateus se esconde atrás do sofá. Bruno inicia a procura e vê que Mateus está atrás do sofá. Nesse instante, toca a campainha e Bruno vai em direção à porta, para atendê-la, Mateus vê que seu amigo foi até a porta, sai correndo e se esconde atrás do armário. Bruno volta e vai em direção ao sofá para procurar Mateus, surpreendendo-se, porque ele não se encontra lá.

Material - O cenário será composto por uma maquete de casa, feita em madeira, dois bonecos, um sofá, um armário.

Quarta história - cena do desenho

Felipe está sentado à mesa, desenhando. O telefone toca e ele vai atender, deixando o desenho e o lápis sobre a mesa. Maurício entra na sala e vê o lápis e o papel do desenho sobre a mesa. Ele os pega da mesa e os coloca dentro da gaveta. Felipe volta, após sua conversa ao telefone, e fica surpreso por não encontrar o lápis e o papel do desenho sobre a mesa.

Material: O cenário será composto por uma maquete de casa, feita em madeira, dois bonecos, um telefone, uma folha de papel, lápis de cor e um armário com gaveta.

\section{Anexo 2 - Tarefas de crença falsa, materiais e procedimentos}

Tarefa 1

A tarefa utilizada foi a da caixa de fósforos (Hogrefe, Wimmer \& Perner, 1986), que consiste na seguinte situação:

O experimentador mostra uma caixa de fósforos para a criança e pergunta o que há dentro da caixa. Quando a criança responde - fósforos -, o experimentador abre a caixa e mostra para a criança outra coisa diferente (refrigerante), que está na caixa, e a fecha. Logo em seguida, ele fala que irá jogar com um amigo(a) da criança e lhe mostrará a caixa de fósforos e perguntará para seu amigo(a) o que tem dentro. Nesse momento, o experimentador faz uma pergunta: "O que ele(a) vai dizer que tem dentro da caixinha, assim que eu perguntar a ele(a), como fiz com você?" "Por que ele(a) dirá isso?" "Você se lembra quando eu mostrei esta caixa a você e perguntei o que tinha dentro dela, o que você respondeu? O que realmente tinha na caixa?"

Material para tarefa: 1 caixa de fósforos e garrafa de refrigerante.

Tarefa 2

A tarefa utilizada na pesquisa foi a de Avis e Harris (1991), que consiste na seguinte situação:

A criança assiste a um boneco fazendo comida. Após o cozimento, ele coloca a comida em uma tigela e cobre com uma tampa e sai da cozinha. Em sua ausência a criança é incitada pelo aplicador a remover a tigela com a comida e esconder em uma panela. Uma vez que a criança esconde a comida, o experimentador faz a seguinte pergunta para a criança: "Qual o primeiro lugar em que o boneco vai procurar a comida, assim que ele voltar? Na tigela ou na panela?" O experimentador pede para a criança justificar sua resposta.

Material para tarefa 2: boneco, comidinha, tigela com tampa e panela com tampa.

Tarefa 3

A tarefa utilizada foi adaptada da tarefa de Perner, Leekam e Wimmer, (1987).

Versão original (Perner, Leekam \& Wimmer, 1987):

Consiste em mostrar, primeiramente, para a criança, uma caixa de "band-aid" vazia e outra caixa igual sem marcas, toda branca, mas com "band-aid" em seu interior. Depois, 
as caixas são fechadas e o boneco é colocado em cena. $\mathrm{Na}$ tarefa de predição, a criança deve predizer em qual caixa o boneco procuraria o "band-aid". Na tarefa de explicação, o boneco começa a olhar a caixa marcada, mas vazia. Solicitase, então, à criança que explique porque o boneco estaria olhando para a caixa vazia.

\section{Versão utilizada:}

O experimentador mostra, primeiramente, para a criança, uma caixa de lápis de cor, vazia, e pergunta o que há dentro. Quando a criança responde, lápis, o experimentador abre a caixa e mostra para a criança que ela está vazia. Ele pega outra caixa igual sem marcas, toda branca, mas com lápis de cor no seu interior e pergunta o que há dentro. Depois que a criança responde, o experimentador abre a caixa e mostra que ela contém lápis de cor. Depois, as caixas são fechadas e entra em cena um o boneco. O pesquisador solicita à criança que diga em qual caixa o boneco vai procurar o lápis de cor. Depois pergunta: "Porque ele foi procurar nesta caixa?" "Onde estão de verdade os lápis?"

Material - 1 caixa de lápis de cor, outra caixa de lápis de cor encapada (sem marcas) e um boneco.

Tarefa 4

A tarefa utilizada foi adaptada da tarefa de Wimmer e Perner (1983)

Versão original (Wimmer \& Perner, 1983):
Maxi ajuda a sua mãe a guardar as compras, coloca seu chocolate no armário verde e sai da cozinha. $\mathrm{Na}$ sua ausência, sua mãe pega o chocolate para colocar um pouco na torta. Depois ela coloca o chocolate no armário azul e sai para comprar ovos. Maxi retorna e quer comer seu chocolate. Nesse momento, o investigador pergunta a criança: "Onde Maxi procurará pelo chocolate? Por quê?"

\section{Versão utilizada:}

João foi fazer compras com sua mãe. Quando voltou, sua mãe pediu para que ele a ajudasse a guardar as compras no armário. João coloca os sucrilhos e o leite no armário e sai para brincar na rua. Na sua ausência, sua mãe pega os sucrilhos e o leite e os guarda em outro armário e sai para comprar ovos, para fazer um bolo. João volta para casa e quer comer seus sucrilhos com leite. Nesse momento, o investigador pergunta à criança: "Qual o primeiro lugar em que João vai procurar o sucrilhos e o leite, assim que ele voltar? No armário em que ele guardou as compras ou onde sua mãe colocou?" O experimentador pede para a criança justificar sua resposta.

Material - 1 caixa de sucrilhos, 1 de leite, uma boneca, um bonequinho, 2 armários e um fogão.

Procedimento de análise das tarefas - para cada resposta não-esperada ou incorreta, foi atribuído 0 (zero) e para cada resposta esperada ou correta foi atribuído o valor 1 (um).
Recebido em: 25/04/2012

Reformulado em: 22/08/2012

$19 / 11 / 2012$

Aprovado em: 23/01/2013

\section{Sobre as autoras}

Simone Ferreira da Silva Domingues (dominguessimone@terra.com.br / simone.domingues@cruzeirodosul.edu.br) Universidade Cruzeiro do Sul / Universidade Guarulhos

Maria Regina Maluf (marmaluf@gmail.com)

Trabalho derivado da tese de doutorado intitulada Teoria da mente: um estudo de intervenção aplicado em crianças de 3 a 4 anos que contou com auxilio financeiro da CAPES.

Endereço para correspondência:

Rua 26 de abril, 118 - apto. 604C -Penha - São Paulo/SP - CEP 03651020 